\title{
Factors related to total cholesterol and blood pressure in British 9 year olds
}

\author{
Roberto J Rona, Sameena Qureshi, Susan Chinn
}

\begin{abstract}
Study objective - To assess which factors are associated with total cholesterol concentration and blood pressure in 9 year olds, and to examine the extent to which a report of a heart attack in a close relative identifies children with a high total cholesterol value or high systolic blood pressure.
\end{abstract}

Design - This was a cross sectional study. Setting - The analysis was based on 22 study areas from a representative English sample, 14 areas from a representative Scottish sample, and 20 areas from an inner city sample.

Participants - There were 1987 children aged 8 or 9 whose blood pressure was measured and 1662 children whose total cholesterol was assessed.

Measurements and main results - Blood pressure was measured using the Dinamap 1846 automated sphygmomanometer and cholesterol using the Lipotrend C. Multiple regression analysis was used to examine the independent associations with each of the outcome variables. Either weight for height or sum of skinfolds measured in four sites was highly associated with the outcome measures in the study $(p<0.001)$. Fatter or overweight children had higher blood pressure and higher cholesterol concentrations. Child's height was also associated with the outcome measures in most of the analyses, but was positively related to blood pressure and negatively associated with cholesterol value. There was an association between diastolic blood pressure and area of residence as represented by the regional health authority (RHA), but the association was not the same as the association reported between coronary heart disease, standardised mortality ratio, and RHA. Children with low birth weight and those with shorter gestation had higher systolic blood pressure $(p<0.05$ and $p<0.01$ respectively), but not diastolic blood pressure. A report of a premature heart attack in a parent or a grandparent was not associated with higher cholesterol or blood pressure.

Conclusions - Reducing obesity in children, together with the avoidance of smoking, may be an appropriate action to prevent coronary heart disease in adulthood. A report of heart disease in a close relative is an ineffective means of identifying children at greater risk of high cholesterol or blood pressure without other measurements from relatives.

\section{(f Epidemiol Community Health 1996;50:512-518)}

There is evidence that people who have cardiovascular risk factors identified in childhood frequently carry these risk factors through into adult life. ${ }^{1-4}$ As coronary heart disease (CHD) and stroke head the list of causes of death in British adults, it is essential to learn about the determinants of blood pressure, cholesterol, and fatness in British children. Blood pressure has been studied in large national samples in England recently, ${ }^{5-8}$ but there has been little information on factors related to lipoproteins in British children. The few studies on serum cholesterol have been carried out in adolescents, ${ }^{9-11}$ small unrepresentative samples, ${ }^{12}$ or risk factors were not studied. ${ }^{10-13}$

There has been some evidence of tracking of blood pressure, but the correlation between measurements carried out over two to six year periods is usually, but not always, low. ${ }^{181415}$ In Britain, a negative relation has consistently been reported between the child's blood pressure and his birth weight, ${ }^{5-716}$ and a positive association with child's weight for height, ${ }^{1617}$ height, ${ }^{5}$ mother's age, ${ }^{16}$ and consistent family clustering of blood pressure. ${ }^{1618}$ There is very little evidence, however, that sociodemographic factors are related to the child's blood pressure. ${ }^{1617}$

Most of the epidemiological studies on total cholesterol and lipoprotein components in childhood have been carried out in the USA over the past 20 years. ${ }^{13412}$ It has been clearly established that most lipoprotein components, including total cholesterol, are tracking at an intermediate level between that of anthropometric measurements such as height and weight for height, and that of blood pressure. ${ }^{1}$ Based on the substantial within child correlation of lipoprotein concentrations over time and the high association between relatives' cholesterol values or early onset of CHD with the child's cholesterol concentration, ${ }^{19-21}$ there have been calls in the USA for population screening or selective screening of children to identify those with high serum cholesterol. The determinants of cholesterol usually studied are restricted to the child's ethnic origin and anthropometric measurements, and risk factors in the family. 
There is little information about the risk factors of high cholesterol in British children and very few published reports. It is important to understand the factors that affect lipoprotein concentrations in Britain because a large variation in cholesterol between countries has been shown, ${ }^{22}$ there is a body of opinion that considers that events early in life and in the prenatal period may affect the chronic disease pattern in adulthood, ${ }^{23}$ and the study of determinants may provide clues to health promotion strategies.

The national study of health and growth (NSHG) assessed the nutritional status of English and Scottish primary school children. Information on CHD risk factors in terms of blood pressure, cardio-respiratory fitness, cholesterol concentration and skinfold thickness at several sites was collected in addition to height and weight in 9 year olds in 1992 and 1993. We have recently reported our findings in relation to cardio-respiratory fitness. ${ }^{24}$ In the analysis now undertaken we assess the associations of social factors, parents' and child's characteristics, such as parental smoking, with the child's blood pressure and cholesterol concentration. We also explore whether a report of premature heart attack in a close relative helps to identify children with high total cholesterol or high systolic blood pressure.

\section{Methods}

The NSHG includes three samples, English and Scottish samples selected by stratified random sampling based on employment exchange areas and an English inner city sample based on 1971 census information at electoral ward level. ${ }^{25}$ As the characteristics of the English and Scottish samples are similar to those of the general population ${ }^{26}$ they will be referred to as the English representative sample and the Scottish representative sample. Information was collected in 22 areas of the English representative sample in 1992, 14 areas of the Scottish representative sample in 1992 or 1993, and 20 areas of the English inner city sample in 1993. Ten study areas in the inner city sample were selected for the high percentage of individuals originally from the Indian subcontinent or from Afro-Caribbean background. The other 10 inner city areas were selected for their high prevalence of overcrowding, male unemployment, or shared house amenities. ${ }^{25}$

Blood pressure, cholesterol concentration, and sum of skinfolds were measured in "the rising 9 children" - ie the classes in which most children were 9 years by the end of the school year in which fieldwork was carried out. A letter and an explanation of all the measurements were sent to the child's parents. The parents had to sign a consent form specifying whether all, some, or no measurements were allowed to be taken. In the rare event that a child whose parent consented to a measurement did not wish to comply with the parents' acceptance, we respected the child's decision. Ethical approval was obtained from all relevant ethical committees in England and Scotland.

\section{ANTHROPOMETRIC DATA}

The children were measured in the school. Height, weight, and triceps and subscapular skinfold thicknesses were measured by a school nurse with $10 \%$ of the measurements checked by a full time field worker from the study team. Biceps and suprailiac skinfold measurements were supervised by a field worker, but no checking of these measurements was made as time in the school was limited. Blood pressure and total serum cholesterol were measured by the field worker. Height was recorded to the last completed $0.1 \mathrm{~cm}$, measured on an especially designed stadiometer (Holtain) using the method recommended by Tanner et al. ${ }^{27}$ Weight was recorded to the last $100 \mathrm{~g}$, with the child wearing only underclothes, using Soenhle digital scales. Skinfold thickness was measured with Harpenden skinfold callipers to the last completed $0.2 \mathrm{~mm}$. Triceps and subscapular skinfolds were measured according to the methods described by Cameron. ${ }^{28}$ The biceps skinfold measurement was made overlying the belly of the biceps muscle at the midpoint of a vertical line joining the humerus with the mid point of the cubital fossa. The suprailiac measurement was made in the mid axillary line, $2.5 \mathrm{~cm}$ above the iliac crest.

\section{BLOOD PRESSURE MEASUREMENT}

Blood pressure was measured using the Dinamap 1846 automated sphygmomanometer in the right arm with an inflatable cuff of small adult size. The mean of the three measurements taken at one minute intervals was used for the analysis. The child was asked to rest at least five minutes before the test.

\section{CHOLESTEROL DETERMINATION}

The cholesterol concentration in capillary blood was measured in the school using the Lipotrend $\mathrm{C}$. The machine is a reflectance photometer for cholesterol assessment in the range 2.6 to $13 \mathrm{mmol} / 1$. The machine calibration was checked at the beginning and the end of each session with a sample of equine serum provided by the manufacturers. The field workers gently squeezed the child's finger proximal to the puncture site filling a capillary tube as recommended. If the capillary tube was not full or an air bubble was detected the sample was discarded and the child was not finger-pricked again. The blood in the capillary tube was transferred to the chemical stick used for analysis in the Lipotrend.

\section{STATISTICS}

In the main analyses stepwise regressions with backward elimination of variables was carried out using the $S A S$ statistical package and the final model included only variables significant at the $5 \%$ level. This approach was taken because there are many a priori hypothesis on the relation between blood pressure and independent variables and, with the exception of obesity, there are very few a priori hypothesis between cholesterol concentration and in- 
Table 1 Geometric mean (95\% confidence intervals) for total cholesterol ( $\mathrm{mmolll}$ ), blood pressure ( $\mathrm{mmHg}$ ), weight for height index ( $\mathrm{kg}$ for $\mathrm{m}$ ), sum of skinfolds $(\mathrm{mm})$ and mean (95\% confidence intervals) height $(\mathrm{cm})$ for children included and those excluded from the multiple regression analysis due to missing values for one independent variable, by sex

\begin{tabular}{|c|c|c|c|c|c|c|c|c|}
\hline \multirow[t]{2}{*}{ Measurements } & \multicolumn{4}{|l|}{ Boys } & \multicolumn{4}{|l|}{ Girls } \\
\hline & No & Mean $(95 \%$ CI) & No & Mean $(95 \% \mathrm{CI})$ & No & Mean $(95 \%$ CI) & No & Mean $(95 \% C I)$ \\
\hline $\begin{array}{l}\text { Cholesterol } \\
\text { Blood pressure }\end{array}$ & 526 & $4.02(3.05,5.30)$ & 290 & $3.98(2.97,5.34)$ & 545 & $4.17(3.15,5.61)^{*}$ & 305 & $4.08(3.04,5.47)$ \\
\hline $\begin{array}{l}\text { Systolic } \\
\text { Diastolic }\end{array}$ & 664 & $\begin{array}{c}109.3(93.6,127.7) \\
57.2(44.3,73.8)\end{array}$ & 339 & $\begin{array}{c}109.5(94.8,126.6) \\
57.7(44.2,75.3)\end{array}$ & 646 & $\begin{array}{c}110.4(94.3,129.3) \\
57.7(44.8,74.4)\end{array}$ & 343 & $\begin{aligned} 110.2 & (91.7,132.7) \\
58.4 & (44.6,76.3)\end{aligned}$ \\
\hline $\begin{array}{l}\text { Height } \\
\text { Weight for height }\end{array}$ & $\begin{array}{l}673 \\
673\end{array}$ & $\begin{array}{r}133.5(121.7,145.3) \\
6.85(4.94,9.49)^{*}\end{array}$ & $\begin{array}{l}374 \\
369\end{array}$ & $\begin{array}{c}133.3(121.0,145.6) \\
6.68(4.87,9.17)\end{array}$ & $\begin{array}{l}660 \\
660\end{array}$ & $\begin{array}{r}133.4(121.2,145.2) \\
7.07(4.93,10.13)\end{array}$ & $\begin{array}{l}367 \\
365\end{array}$ & $\begin{array}{r}132.9(120.7,145.2) \\
7.13(5.46,11.17)\end{array}$ \\
\hline Sum of skinfolds & 673 & $31.1(14.3,67.4)$ & 349 & $29.8(14.0,63.2)$ & 660 & $40.2(19.4,83.4)$ & 335 & $42.3(18.2,97.3)$ \\
\hline
\end{tabular}

${ }^{*} \mathrm{p}<0.05$ between included and excluded.

dependent variables in children. Three dependent variables were analysed: systolic and diastolic blood pressure, and cholesterol concentration each log transformed to reduce skewness. The independent variables were: sex, ethnic origin and English or Scottish sample, father's social class based on occupation, mother's education level, number of children, child's length of pregnancy and birth weight, total parental smoking at home, whether mother smoked in pregnancy, maternal and paternal body mass index (BMI) as calculated from reported heights and weights, mother's age at the child's birth, NHS regional health authorities before the 1993 reorganisation, and child's height, weight for height using the index [(weight -9$) /$ height $\left.^{3.7}\right]^{29}$ (weight for height), sum of skinfolds, skinfold distribution - ie (biceps + triceps skinfolds)/(subscapular + suprailiac skinfolds). Parents' BMI and the child's measurements, each log-transformed except for height, were included as continuous variables, and the rest were included as categorical variables. Information on social, demographic background, behavioural and biological characteristics of the parents, and the child's length of gestation and birth weight were ob-

Table 2 Factors associated with cholesterol concentration (log mmol/l) using stepwise regression with backward elimination in children, with coefficient unadjusted for other variables and adjusted as in the final model

\begin{tabular}{|c|c|c|c|c|c|}
\hline \multirow[b]{3}{*}{ Independent variable } & \multirow[b]{3}{*}{ No } & \multicolumn{4}{|c|}{ Total $(n=1071)$} \\
\hline & & \multicolumn{2}{|l|}{ Unadjusted } & \multicolumn{2}{|l|}{ Adjusted } \\
\hline & & Coefficient & $p$ value & $\dot{C}$ oefficient & $p$ value \\
\hline Intercept & & & & 0.7074 & \\
\hline Log sum of skinfolds (mm) & & 0.0565 & $<0.001$ & 0.0603 & $<0.001$ \\
\hline Height $(\mathrm{cm})$ & & -0.0006 & 0.074 & -0.0013 & $<0.001$ \\
\hline Sex & & & $<0.001$ & & 0.028 \\
\hline Boys & 526 & -0.0160 & & -0.0087 & \\
\hline Girls & 545 & 0.0000 & & 0.0000 & \\
\hline Ethnic origin & & & $<0.001$ & & $<0.001$ \\
\hline White (inner city) & 122 & 0.0224 & & 0.0200 & \\
\hline Afro-Caribbean & 38 & 0.0182 & & 0.0231 & \\
\hline Urdu & 15 & 0.0008 & & -0.0032 & \\
\hline Gujurati & 15 & -0.0276 & & -0.0291 & \\
\hline Punjabi & 30 & 0.0309 & & 0.0301 & \\
\hline Other (Indian subcontinent) & 13 & 0.0401 & & 0.0398 & \\
\hline Others & 29 & 0.0078 & & 0.0076 & \\
\hline White (Scottish) & 337 & 0.0101 & & 0.0096 & \\
\hline White (English) & 472 & 0.0000 & & 0.0000 & \\
\hline Child's birth weight (g) & & & 0.389 & & 0.074 \\
\hline$<2500$ & 76 & -0.0067 & & -0.0140 & \\
\hline $2500-2999$ & 205 & -0.0122 & & -0.0180 & \\
\hline $3000-3499$ & 423 & -0.0133 & & -0.0189 & \\
\hline $3500-3999$ & 267 & -0.0101 & & -0.0129 & \\
\hline$\geq 4000$ & 100 & 0.0000 & & 0.0000 & \\
\hline No of children & & & 0.010 & & 0.034 \\
\hline 1 & 80 & 0.0062 & & 0.0082 & \\
\hline 2 & 462 & -0.0155 & & -0.0099 & \\
\hline 3 or 4 & 374 & -0.0049 & & -0.0017 & \\
\hline 5 or more & 97 & -0.0141 & & -0.0141 & \\
\hline Not known & 58 & 0.0000 & & 0.0000 & \\
\hline Explained variation $\left(\mathbf{R}^{2}\right)$ & & & & $7.6 \%$ & \\
\hline
\end{tabular}

tained from a self administered questionnaire completed by the parent. In consideration of the interest in the association between birth weight and CHD risk factors, birth weight was added to a final model as a categorical variable and retained if significant at the $10 \%$ level. In the multiple regression analyses the interaction of sex with the other independent variables were tested to decide whether to present results by sex. The interaction of number of children and ethnic origin was also included because this interaction had been detected in a number of analyses of anthropometric variables.

\section{Results}

Altogether 2581 children were eligible for the study, 829 from the English representative sample, 520 from the Scottish representative sample, and 1232 from the English inner city areas. Blood pressure was measured in 1992 $(77 \%)$ and total cholesterol was measured in $1666(65 \%)$ children. In the stepwise regression analysis, further losses occurred as for some continuous variables no information was obtained. Paternal heights and weights were poorly completed in the questionnaire and to minimise losses children for whom data on the father's BMI was missing were included after elimination of father's BMI from the model. Table 1 gives the geometric means for total cholesterol, systolic and diastolic blood pressure, sum of skinfolds and weight for height, and the mean height for children who were included in the stepwise regression and those who were not included, in relation to sex. Boys who were included in the analysis were significantly heavier than those who were not included $(p<0.05)$. Girls in the analysis had a significantly higher cholesterol concentration than the rest $(\mathrm{p}<0.05)$.

Table 2 shows the variables in the final model which were significantly associated with cholesterol concentration, and the size of effect adjusted and unadjusted for the other variables in the model. Interaction terms were not significant except that the interactions of sex with father's BMI, and sex with total parental smoking at home, were weakly significant in the smaller sample which included children with data on father's BMI. Table 2 shows both sexes together in the larger sample as there was no clear evidence that there was a genuine difference between the sexes. Log sum of skinfolds was highly significantly and positively associated with total cholesterol $(p<0.001)$. 
Table 3 Factors associated with systolic blood pressure (log $\mathrm{mm}$ ) using stepwise regression with backward elimination in children, with coefficient unadjusted for other variables and adjusted as in the final model

\begin{tabular}{|c|c|c|c|c|c|}
\hline \multirow[b]{3}{*}{ Independent variable } & \multirow[b]{3}{*}{ No } & \multicolumn{4}{|c|}{ Total $(n=1310)$} \\
\hline & & \multicolumn{2}{|l|}{ Unadjusted } & \multicolumn{2}{|l|}{ Adjusted } \\
\hline & & Coefficient & $p$ value & Coefficient & $p$ value \\
\hline Intercept & & & & 1.7602 & \\
\hline Height $(\mathrm{cm})$ & & 0.0016 & $<0.001$ & 0.0014 & $<0.001$ \\
\hline Log weight for height ( $\mathrm{kg}$ for $\mathrm{m}$ ) & & 0.1381 & $<0.001$ & 0.1262 & $<0.001$ \\
\hline Birth weight $(\mathrm{kg})$ & & -0.0017 & 0.347 & -0.0041 & 0.027 \\
\hline Length of gestation: & & & 0.005 & & 0.002 \\
\hline$\leq 37 \mathrm{wk}$ & 162 & 0.0097 & & 0.0083 & \\
\hline$\geq 38 \mathrm{wk}$ & 991 & 0.0002 & & 0.0001 & \\
\hline Not known & 167 & 0.0000 & & 0.0000 & \\
\hline Ethnic origin & & & 0.016 & & 0.044 \\
\hline White (inner city) & 157 & -0.0087 & & -0.0090 & \\
\hline Afro-Caribbean & 49 & 0.0030 & & -0.0055 & \\
\hline Urdu & 16 & 0.0081 & & 0.0048 & \\
\hline Gujurati & 15 & -0.0174 & & -0.0091 & \\
\hline Punjabi & 34 & -0.0043 & & 0.0043 & \\
\hline Other (Indian subcontinent) & 14 & 0.0104 & & 0.0073 & \\
\hline Others & 34 & -0.0014 & & 0.0004 & \\
\hline White (Scottish) & 383 & 0.0026 & & 0.0025 & \\
\hline White (English) & 608 & 0.0000 & & 0.0000 & \\
\hline Explained variation $\left(\mathbf{R}^{2}\right)$ & & & & $17 \%$ & \\
\hline
\end{tabular}

Table 4 Factors associated with diastolic blood pressure (log mm) using stepwise regression with backward elimination in children, with coefficient unadjusted for other variables and adjusted as in the final model

\begin{tabular}{|c|c|c|c|c|c|}
\hline \multirow[b]{3}{*}{ Independent variable } & \multirow[b]{3}{*}{ No } & \multicolumn{4}{|c|}{ Total $(n=1310)$} \\
\hline & & \multicolumn{2}{|l|}{ Unadjusted } & \multicolumn{2}{|l|}{ Adjusted } \\
\hline & & Coefficient & p value & Coefficient & $p$ value \\
\hline \multirow{4}{*}{\multicolumn{2}{|c|}{$\begin{array}{l}\text { Intercept } \\
\text { Height }(\mathrm{cm}) \\
\text { Log sum of skinfolds (mm) } \\
\text { Father's social class }\end{array}$}} & & & 1.4866 & \\
\hline & & 0.0020 & $<0.001$ & 0.0016 & $<0.001$ \\
\hline & & 0.0623 & $<0.001$ & 0.0446 & $<0.001$ \\
\hline & & & 0.001 & & 0.003 \\
\hline Non-manual & 362 & -0.0014 & & -0.0066 & \\
\hline Manual & 567 & -0.0108 & & -0.0121 & \\
\hline Not applicable & 263 & -0.0176 & & -0.0165 & \\
\hline \multirow{9}{*}{$\begin{array}{l}\text { No of children } \\
1 \\
2 \\
3 \text { or } 4 \\
5 \text { or more } \\
\text { Not known } \\
\text { Regional health authorities } \\
\text { Explained variation }\left(R^{2}\right)\end{array}$} & 118 & 0.0000 & & 0.0000 & \\
\hline & & & 0.008 & & 0.009 \\
\hline & 105 & -0.0080 & & -0.0017 & \\
\hline & 566 & 0.0034 & & 0.0114 & \\
\hline & 448 & -0.0089 & & 0.0020 & \\
\hline & 121 & -0.0073 & & 0.0048 & \\
\hline & 70 & 0.0000 & & 0.0000 & \\
\hline & & & $<0.001$ & * & $<0.001$ \\
\hline & & & & $11.9 \%$ & \\
\hline
\end{tabular}

* 14 regional levels are not given.

Table 5 Geometric means (95\% confidence interval) of cholesterol concentration (mmol/l) and systolic blood pressure $(\mathrm{mmHg})$ according to information on heart attack before age 65 in child's parents or grandparents

\begin{tabular}{|c|c|c|c|c|}
\hline \multirow[t]{2}{*}{ Heart attack } & \multicolumn{2}{|l|}{ Boys } & \multicolumn{2}{|c|}{ Girls } \\
\hline & No & Mean $(95 \% C I)$ & No & Mean $(95 \%$ CI) \\
\hline \multicolumn{5}{|c|}{ Cholesterol concentration } \\
\hline $\begin{array}{l}\text { Yes } \\
\text { No } \\
\text { Not known }\end{array}$ & $\begin{array}{l}205 \\
260 \\
319\end{array}$ & $\begin{array}{l}4.07(3.18,5.23) \\
4.05(3.07,5.34) \\
3.95(2.91,5.35)\end{array}$ & $\begin{array}{l}292 \\
206 \\
336\end{array}$ & $\begin{array}{l}4.17(3.11,5.58) \\
4.15(3.13,5.51) \\
4.14(3.12,5.49)\end{array}$ \\
\hline \multicolumn{5}{|c|}{ Systolic blood pressure } \\
\hline $\begin{array}{l}\text { Yes } \\
\text { No } \\
\text { Not known }\end{array}$ & $\begin{array}{l}260 \\
294 \\
422\end{array}$ & $\begin{array}{ll}109.2 & (94.1,126.6) \\
109.3 & (93.0,128.4) \\
109.4 & (94.7,126.5)\end{array}$ & $\begin{array}{l}327 \\
232 \\
409\end{array}$ & $\begin{array}{ll}109.9 & (92.7,130.1) \\
110.9 & (94.6,129.9) \\
110.3 & (92.6,131.4)\end{array}$ \\
\hline
\end{tabular}

Height was highly significantly and negatively associated with total cholesterol $(p<0.001)$. Boys had lower cholesterol concentrations than girls $(p<0.05)$. Those who were the only child in the family had higher cholesterol than children in larger families $(p<0.05)$. White children in inner city areas had higher cholesterol than other white children, and children in the other (Indian Subcontinent) and Punjabi groups had higher total cholesterol. Child's birth weight divided into five groups was marginally significant $(p=0.07)$, the heaviest children having the highest total cholesterol. Unadjusted birth weight was not associated with the total cholesterol concentration.

Tables 3 and 4 give the variables in the final models which were significantly associated with systolic and diastolic blood pressures respectively in children, and size of effect without and with adjustment for the other variables in the model. None of the interactions was significant, except in the smaller sample, including those with data on father's BMI; the interaction of sex and mother's smoking in pregnancy was significant in the analysis of systolic blood pressure. Height and the log weight for height index or level of fatness were consistently and highly associated with blood pressure $(p<0.001)$. Tall and overweight or fat children had higher blood pressure. Birth weight as a continuous variable was associated with systolic blood pressure only $(p<0.05)$. Children who had a shorter length of gestation had higher systolic blood pressure than the rest of the children $(p<0.01)$. The regional location of the study areas was related to diastolic blood pressure, but the association was not related to CHD mortality in the regions ${ }^{3031}$. Diastolic blood pressure was higher in children whose fathers did not disclose their occupation $(p<0.01)$. There was a significant association between systolic blood pressure and ethnic origin $(p<0.05)$. Southeast Asians, with the exception of Gujarati children, tended to have a higher level. Birth weight was not significantly associated with systolic or diastolic blood pressure at the $5 \%$ level, either when analysed as continuous variable or divided in five categories as shown in table 2, when unadjusted for other factors.

The geometric mean of cholesterol and systolic blood pressure in boys and girls, based in all available data, did not vary significantly in relation to a reported heart attack below the age of 65 in parents or grandparents (table 5). The relative risk of a cholesterol concentration of at least $5.0 \mathrm{mmol} / 1$ in children for whom at least one parent or grandparent had a heart attack under the age of 65 was 0.92 (95\% CI $0.46,1.80)$ in boys and $1.23(95 \%$ CI 0.76 , 2.00 ) in girls. Likewise, the relative risk of a systolic blood pressure level of at least $120 \mathrm{~mm}$ in children with at least one parent or grandparent who had had a heart attack was 0.94 $(95 \% \mathrm{CI} 0.59,1.48)$ in boys and $0.90(95 \% \mathrm{CI}$ $0.6,1.32)$ in girls.

\section{Discussion}

The most consistent finding in this study is that heavier or fatter children had higher systolic and diastolic blood pressures and cholesterol concentrations. Taller children had a higher blood pressure than other children and smaller children had higher cholesterol concentration. There were significant associations between diastolic blood pressure levels and regional health authorities, which were unrelated to CHD mortality statistics for the regions. ${ }^{3031}$ Children with a low birth weight had a higher systolic blood pressure and those with a shorter length of gestation had a higher systolic blood pressure. However, diastolic blood pressure 
was not associated with birth weight. Information on a premature heart attack in parents or grandparents did not help to identify children with either higher cholesterol concentrations or blood pressure levels.

In this study the low percentage of children in the analysis in comparison to the number of eligible children was related to two factors. Firstly, the requirement of a positive consent from parents to allow the child to be measured, and secondly the low rate of completed questionnaires in the inner city sample areas. The percentage of children who were finger-pricked (between 62 and 68\%) was not different to the percentage in our pilot studies and other surveys in adults in which a blood sample was required. ${ }^{32}$ The procedure we followed to obtain blood was geared to minimise the risk that any parent or helper could have interpreted our actions as putting undue pressure on a child to collaborate with our study. Approval for the study was obtained from all the relevant ethics committees in England and Scotland, and we complied with all their special requirements. The response rate in inner city areas has traditionally been lower, especially in London, than in other places in our survey over time.

Blood pressure, blood cholesterol, and biceps and suprailiac skinfold thickness measurements were piloted in three primary schools not in the NSHG to assess feasibility and, with the exception of cholesterol, the repeatability. The level of agreement in total cholesterol using the Lipotrend was assessed using blood from a finger-pricked sample and venepuncture sample in 25 members of the Department of Public Health Medicine. In the adult sample, comparisons were also made between total cholesterol concentrations using the Lipotrend C and measurement in St Thomas's chemical pathology laboratory using the same sample from venepuncture. The intraclass correlations for skinfold thickness measurements in primary school children were above 0.9 , the intraclass correlation for systolic blood pressure was 0.6 and for diastolic blood pressure was 0.3 on one occasion and 0.6 on a second occasion. The mean difference between samples in the adult group using the Lipotrend $C$ was $0.02 \mathrm{mmol} / \mathrm{l}$ (SD 0.39) when repeated from capillary samples and $0.05 \mathrm{mmol} / 1(0.32)$ when venous and capillary samples were compared. There was a significant difference between laboratory and Lipotrend $\mathrm{C}$ measurements of $0.90 \mathrm{mmol} / 1$ (0.44), but the ranking of subjects by cholesterol concentration with the two methods was similar. Thus, measurements using the Lipotrend $\mathrm{C}$ are consistent and highly repeatable, but the results given above should not be used as British standards as they may underestimate laboratory determinations by approximately $15 \%$.

A further consideration in the results presented is that only one cuff size was used in the study. The American Heart Association recommended a change to a larger cuff when width in relation to arm circumference falls below $40 \%$. However, Whincup et $a l^{33}$ disagreed with the advice. They showed that a large difference in blood pressure occurred with the change of cuff size with greater arm circumference. This difference in blood pressure changed little after adjustment for arm circumference. In fact, the effect of arm circumference, using the Dinamap, was not significant for systolic blood pressure and just significant for diastolic blood pressure in their study. $^{33}$

The finding that heavier or fatter children have higher blood pressure and cholesterol concentrations is not new. In his literature review of 1979, Szklo $^{14}$ quoted 10 references of studies in children who had shown a significant association between blood pressure and overweight. More recently similar findings have been reported in the Muscatine and the Bogalusa studies in the USA, ${ }^{34}$ and in Britain, the finding has been also confirmed. ${ }^{6}$ The Muscatine and the Bogulasa studies have also shown a high association between overweight or overweight gain and cholesterol concentration. ${ }^{3637}$ Lauer et $a l^{\beta 8}$ have also reported that obesity in adolescence leads to higher cholesterol in adulthood. In our analysis, the ratio of limb to body skinfold thickness, an analogue of ratio of the waist to hip ratio, was unrelated to serum cholesterol or blood pressure. In the health examination survey in the USA, the ratio of waist to hip ratio was reported to be significantly associated with blood pressure. ${ }^{39}$ However, the ratio was significantly associated only with diastolic blood pressure in a multiple regression analysis in the age group 6-11 years. In the older group, 12-17 years, the waist to hip ratio was not associated with cholesterol concentration, but a significant association was detected with systolic blood pressure. It is possible that the distribution of fat as a risk factor of high blood pressure and cholesterol starts to be an important contributory factor in adolescence and adulthood, while fatness and overweight are permanent risk factors throughout life. In practical terms, the assessment of obesity should be considered an important component in the prevention of conventional CHD risk factors, as its assessment is not invasive and it is acceptable to the community.

Our analysis confirms the association, albeit only moderate in comparison to fatness, between systolic blood pressure and birth weight reported by others. ${ }^{67164041}$ Both birth weight and length of pregnancy were found in our analysis to be associated with systolic blood pressure, but not diastolic blood pressure. Other authors have adjusted for current weight to assess the association between blood pressure and birth weight. However weight per se is a poor anthropometric measurement, as it is not interpretable without adjustment for height. It is more appropriate, as carried out in our study, to include a measure that reflects general nutritional status, such as height and measures of obesity or overweight. We used two measures of obesity, weight for height and sum of skinfolds, because these permit an inference as to whether fat itself or a more complex function of body build is related to blood pressure. Using this strategy, blood pressure was not consistently associated with birth 
weight. In the papers published by Barker et al the relation between birth weight and blood pressure is more marked in adults. ${ }^{73940}$ Whincup et al found an association between systolic blood pressure and birth weight adjusting for body mass index in 5 to 7 year olds. In their earlier study, the association only appeared after adjusting for current weight. ${ }^{16}$ They also reported in that study an association between diastolic blood pressure and birth weight. In our analysis birth weight was not associated with diastolic blood pressure.

In this analysis cholesterol and birth weight were associated just above the conventional 5\% significance level when birth weight was divided into five groups. The analysis indicated that heavier babies may have higher cholesterol. Low birthweight children are not worse off than other children in relation to other CHD risk factors such as total cholesterol concentration and cardio-respiratory fitness, a not entirely accepted proxy measure of physical activity. ${ }^{24}$ Thus, from this analysis birth weight has a very limited potential for affecting CHD morbidity and mortality. This does not preclude the possibility that maternal nutrition in pregnancy has a more convincing association with CHD risk factors in adults. In his analysis of adult CHD risk factors, Barker et al reported a positive association between birth weight and cholesterol concentration and a negative association with weight at 1 year. ${ }^{42}$ This was attributed to the advantages of breast feeding for at least a year. This cannot easily be tested with current data in children as they are rarely breastfed for such a long time.

In this analysis we included several sociodemographic factors. Although some significant associations were detected, none can be construed as having a biological meaning as they were inconsistent.

We were interested to ascertain whether information of a possible premature myocardial infarction in a close relative identifies children with high cholesterol or blood pressure. In the USA recommendations have been made that children from high risk families should be screened for raised cholesterol. ${ }^{43}$ Some researchers want to extend the screening programme to the whole population based on the large percentage of children with a high cholesterol concentration with no family history because a large number of children are missed with the first strategy. ${ }^{44}$ Dennison et al ${ }^{20}$ demonstrated that in white children, but not black children, there was an association between parental history of heart attack or diabetes mellitus and the child's cholesterol concentration. An Austrian study showed that children whose parents had myocardial infarction had a higher lipoprotein $\operatorname{Lp}(a) .^{45}$ Our results indicate that a history of myocardial infarction provided by the child's parents does not identify children at higher risk to have greater blood pressure or higher cholesterol concentrations. Even if the association were meaningful the number of parents with a "heart attack" in the study was low and we also needed to collect information about grandparents. This lowers the value of the information as the child's parents may have limited knowledge of health problems in their parents and both genes and environment are less similar between grandparent and child than between parent and child. Only by collecting more information on family history and measuring the cholesterol concentration might the strategy identify children at high risk, but even then it would be very costly and inefficient and we think, along with others who are against childhood screening in the USA, ${ }^{46}$ ineffective and possibly damaging.

In conclusion, reducing obesity in children, together with the avoidance of smoking, may be the most appropriate action to prevent coronary heart disease in adulthood, because it is consistently associated with cholesterol and blood pressure levels and fitness level in children, and can be easily diagnosed by health workers in the community with minimal cost. However, to reverse the current increase of obesity in British children ${ }^{47}$ and adults ${ }^{32}$ we need to develop creative and effective interventions in the community.

The authors thank our colleagues in the team and all parents children and helpers in the study areas. The study is funded through the Department of Health and the Scottish Home and Health Department.

1 Clarke WR, Schrott HG, Leaverton PE, Connor WE, Lauer RM. Track of blood lipids and blood pressures in school age children: the Muscatine study. Circulation 1978;58: 626-34.

2 Lauer RM, Lee J, Clarke WR. Factors affecting the relationship between childhood and adult cholesterol levels: the Muscatine study. Pediatrics 1988;82:309-18.

3 Webber LS, Srinivasan SR, Wattigney WA, Berenson GS Tracking of serum lipids and lipoproteins from childhood to adulthood: the Bogalusa heart study. Am $\mathcal{F}$ Epidemiol 1991;33:884-98.

4 Bao W, Srinivasan SR, Berenson GS. Tracking of serum apolipoproteins $A-I$ and $B$ in Children and young adults: the Bogolusa heart study. FClin Epidemiol 1993;46:609-16.

5 Whincup PH, Cook DG, Papacosta $O$ and Walker $M$. Childhood blood pressure, body build, and birthweight: geographical associations with cardiovscular mortality. $\mathcal{f}$ Epidemiol Community Health 1992;46:396-402.

6 Whincup PH, Cook DG, Papacosta O. Do maternal and intrauterine factors influence blood pressure in children. Arch Dis Child 1992;67:1423-9.

7 Law CM, De Swiet M, Osmond C, Fayers PM, Barker DJP, Cruddas AM, Fall CHD. Initiation of hypertension in utero and its amplification throughout life. BMF 1993; 306:24-7

8 De Swiet M, Fayers P, Shinebourne EA. Blood pressure in first 10 years of life: the Brompton study. $B M \mathcal{F}^{\prime} 1992 ; 304$ 23-6.

9 Orchard TJ, Rodgers M, Hedley AJ, Mitchell JRA. Changes in blood lipids and blood pressure during adolescence. BMF 1980;280:1563-7.

10 Amstrong N, Balding J, Gentle P, Kirby B. Estimation of coronary risk factors in British children: a preliminary report. Br $\mathcal{F}$ Sports Med 1992;24:61-6.

11 Sporik R, Johnstone JH, Cogswell JJ. Longitudinal study of cholesterol values in 68 children from birth to 11 years of age. Arch Dis Child 1991;66:134-7.

12 Hammond J, Chinn S, Richardson $H$, Rona R. Serum total cholesterol and ferritin and blood haemoglobin concentrations in primary schoolchildren. Arch Dis Child 1994; 70:373-5.

13 Boreham C, Savage JM, Primrose D, Cran G, Strain J. Coronary risk factors in schoolchildren. Arch Dis Child 1993;68:182-6.

14 Szklo M. Epidemiological patterns of blood pressure in children. Epidemiol Rev 1979;1:143-69.

15 Beckett LA, Rosner B, Roche, Guo S. Serial changes in blood pressure from adolescent into adulthood. $A m$ Epidemiol 1992;135:1166-77.

16 Whincup PH, Cook DG, Shaper AG. Early influences on blood pressure: a study of children aged 5-7 years. $B M^{9}$ 1989:299:587-91.

17 Holland WW, Beresford SAA. Factors influencing blood pressure in children. In: Paul $O$, ed. Epidemiology and control of hypertension. Second International Symposium on the epidemiology of hypertension. London: Symposia Specialist
1974 . 1974. pressure levels. 7 Epidemiol Community Health 1980;34: $168-73$.

19 Croft JB, Cresanta JL, Webber LS, Srinivasan SR, Freed- 
man, Burke GL, Beenson GS. Cardiovascular risk in parents of children with extreme lipoprotein cholesterol levels: the Bogalusa heart study. Southern Med 71989 ; 115:341-9.

20 Dennison BA, Kikuchi DA, Srinivasan SR, Webber LS, Berenson GS. Parental history of cardiovascular disease as an indication for screening for lipoprotein abnormalities in children. $\mathcal{F}$ Pediatrics 1989;115:186-94.

21 Rosenbaum PA, Elston RC, Srinivasan SR, Webber LS, Berenson GS. Cardiovascular risk factors from birth to Berenson GS. Cardiovascular risk factors from birth to rt study. Predictive value of parental measures in determining cardiovascular
risk factor variables in early life. Pediatrics 1987;80:807-16.

22 Kuninan JT, Hermus RJ, Hautvast JGAJ. Serum total and high density lipoprotein (HDL) cholesterol concentrations in rural and urban boys from 16 countries. Atherosclerosis 1980;36:529-37.

23 Barker DJB ed. Fetal and infant origins of adult disease. London: BMJ Publishing Group 1992.

24 Kikuchi S, Rona RJ, Chinn S. Physical fitness of 9 year olds in England: related factors. $\mathcal{F}$ Epidemiol Community Health 1995;49:180-5.

25 Rona RJ, Chinn S. National Study of Health and Growth: social and biological factors associated with height of children from ethnic groups living in England. Ann Hum Biol 1986;13:453-71.

26 Rona RJ, Altman DG. National Study of Health and Growth: Standards of attained height, weight and triceps skinfold in English children 5 to 11 years old. Ann Hum Biol 1977;6:501-23.

27 Tanner JM, Whitehouse RH, Takaishi M. Standards from birth to maturity for height, weight, height velocity and weight velocity: British children, 1965. Part I. Arch Dis Child 1966;41:454-71.

28 Cameron $\mathrm{N}$. The methods of auxological anthropometry. In Falkner F, Tanner JM (eds.) Human growth. A comprehensive treatise. Vol 3 Methodology, ecological, genetic, and nutritional effects on growth. 2nd ed. London: Plenum Press, 1986:3-46.

29 Chinn S, Rona RJ, Gulliford MC, Hammond J Weight for height in children aged 4 to 12 years. Eur $\mathcal{F}$ Clin Nut 1992; 46:489-500.

30 OPCS. 1992 Mortality statistics. Area series DH5 no 19. London: HMSO 1994.

31 OPCS. 1991 Mortality statistics. General. Series DH1 no 26. London: HMSO 1993.

32 Gregory J, Foster K, Tyler H, Wiseman M. The dietary and nutritional survey of British adults. London: Social Survey Division, OPCS, HMSO, 1990:392.

33 Whincup PH, Cook DG, Shaper AG. Blood pressure measurement in children: the importance of cuff bladder size. F Hypertension 1989;7:845-50.

34 Lauer RM, Burns TL, Clarke WR, Magoney LT. Childhood predictors of future blood pressure. Hypertension 1991; 18(suppl I):74-81.

35 Webber LS, Harsha DW, Phillips GT, Srinivasan SR, Simpson JW, Berenson GS. Cardiovascular risk factors in hispanic, white, and black children: The Brooks County heart studies. Am 7 Epidemiol 1991;133:704-14.

36 Freedman DS, Srivivasan SR, Cresanta JL, Webber LS, Berenson GS. Serum lipids and lipoproteins. Pediatrics Berenson GS. Serum lip

37 Burns TL, Moll PP, Lauer RM. The relation between ponderosity and coronary risk factors in children and their relatives. The Muscatine ponderosity family study. $\operatorname{Am~} \mathcal{f}$ Epidemiol 1989;129:973-87.

38 Lauer RM, Lee J, Clarke WR. Predicting adult cholesterol levels from measurements in childhood and adolescence: the Muscatine study. Bull NY Acad Med 1989;65:1127-42.

39 Gillum RF. The association of the ratio of waist to hip girth with blood pressure, serum cholesterol and serum uric acid in children and youth aged 6-17 years. 7 Chron Dis 1987;40:413-20.

40 Barker DIP, Osmond C, Golding J, Kuh D, Wadsworth MEJ. Growth in utero, blood pressure in childhood and adult life, and mortality from cardiovacular disease. BMF 1989;298:564-7.

41 Barker DJP, Bull AR, Osmond C, Simmonds SF. Fetal and placental size and risk of hypertension in adult life. $B M \mathcal{F}$ 1990;301:259-62.

42 Fall CHD, Barker DJP, Osmond C, Winter PD, Clark PMS, Hales CN. 25: Relation of infant feeding to adult serum cholesterol concentration and death from ischaemic heart disease. In Barker DJP ed. Fetal and infant origins of adult disease. London: BMJ Publishers, 1992:275-8.

43 American Academy of Pediatrics Committee on Nutrition. Indications for cholesterol testing in children. Pediatrics 1989;83:141-2.

44 Garcia RE, Moodie DS. Routine cholesterol surveillance in childhood. Pediatrics 1989;84:751-5.

45 Hoefler G, Harnoncourt F, Paschke E, Mirtl W, Pfeiffer $\mathrm{KH}$, Kostner GM. Lipoprotein Lp(a). A risk factor for myocardial infarction. Arteriosclerosis 1988;8:398-401

46 Newman TB, Browner WS, Hulley SB. The case against childhood cholesterol screening. $¥ A M A$ 1990;264:303943.

47 Chinn S, Rona RJ. Trends in weight-for-height and triceps skinfold thickness for English and Scottish children, 1972-82 and 1982-1990. Paediatr Perinat Epidemiol 1994; 8:90-106. 